\title{
Complementarities in CSO Collaborations: How Working with Diversity Produces Advantages
}

\author{
Margit van Wessel ${ }^{1}\left[\right.$ [ Farhat $\mathrm{Naz}^{2} \cdot$ Sarbeswar Sahoo $^{3}$
}

Published online: 4 May 2020

(C) The Author(s) 2020

\begin{abstract}
A commonly explored theme in international civil society organisation (CSO) collaborations is the dominance of Northern CSOs and how this impinges on Southern CSOs' autonomy, but there is little work on the relative importance of different collaborations for Southern CSOs. This study examined complementarity as a new approach to understanding CSO collaboration. Seeking Southern perspectives, we examined the case of CSOs working on disaster risk reduction in India and developed a typology of complementarities in this domain. The article considers the implications for understanding complementarity in broader CSO collaborations. We find that constructing collaborations through the lens of complementarity may facilitate capitalising on diversity among CSOs and help build collaborations that consider the domestic orientation of many Southern CSOs and reshape the roles of Northern CSOs as complementary rather than leading.
\end{abstract}

Keywords Collaboration · Complementarity · Civil society organisations $\cdot$ Disaster risk reduction $\cdot$ Southern leadership

Margit van Wessel

margit.vanwessel@wur.nl

Farhat Naz

farhat@iitj.ac.in

Sarbeswar Sahoo

sarbeswar@hss.iitd.ac.in

1 Wageningen University and Research, Wageningen, The Netherlands

2 Indian Institute of Technology Jodhpur, Jodhpur, India

3 Indian Institute of Technology Delhi, Delhi, India

\section{Exploring Southern Perspectives on Advocacy Collaborations}

Existing scholarship on advocacy collaborations among civil society organisations (CSOs) has primarily focused on high-profile transnational campaigns carried out by transnational advocacy networks and partnerships (see, e.g. Bob 2007; Jordan and Van Tuijl 2000; Keck and Sikkink 2014; Wong 2012). This has yielded insight into the dynamics of such relations. Northern CSOs' dominance in defining agendas and understandings regarding issues and solutions has often been explored, as has how this impinges on Southern CSOs' capacity to play an autonomous role, representing constituencies, articulating issues, setting agendas and carrying out their work as they choose (Jalali 2013; Jordan and Van Tuijl 2000). However, we know little about how Southern CSOs see the nature and role of different forms of collaboration with various types of CSOs. Depending on multiple conditions such as state context, thematic focus and capacity, CSOs are exposed to a range of opportunities for collaboration at local, national and international levels, but very little research has focused on the relative importance of different collaborations for Southern CSOs considering the multiple opportunities to which they are exposed (Van Wessel et al. 2018).

We also know little about how different considerations factor in for Southern CSOs as they contextually engage with different opportunities for collaboration. To understand the role of collaborations for Southern CSOs, we need to explore how collaboration possibilities shape CSOs' roles as they interact, exchange resources, and navigate opportunities, dependencies and constraints in their international- and domestic-level collaborations. This exploration should be based on the organisations' own interpretations of the nature and significance of different 
CSOs and forms of collaboration. The relative role of different opportunities for collaboration-domestic and international-can then become clear. In addition to shedding more light on international collaborations, which have generally been centre stage in existing research, this approach can reveal diversity in CSOs' engagement in broader civil society collaborations.

In this article, we examine the relative role of different collaboration opportunities by exploring the nature of complementarity among CSOs. We focus on complementarity in advocacy collaborations and define this complementarity as two or more different qualities, capacities or resources of CSOs coming together in advocacy and contributing to reaching the objectives of the CSOs involved. With this definition, we partially draw on conceptualisation of complementarity in relational terms of comparative advantage leading to mutual benefit (see, e.g. Coston 1998), but focus more distinctly on the types of contributions to attainment of objectives to which the complementarities can contribute. Our more content-focused concept of complementarity can help guide and support civil society advocacy in three ways, helping CSOs and other actors such as donors to (1) do more justice to CSO diversity as functional for addressing societal issues, (2) work from the principle of ownership and (3) facilitate Southern leadership.

We explore complementarity in collaborations among CSOs working on disaster risk reduction (DRR) in India. Although the case is limited in scope, it can serve as a proof of principle and encourage further analysis and uptake of complementarity as a guiding concept. We approach Southern CSOs as agents entering collaborations with their own perspectives, based on their understandings of their realities and possibilities, and devising strategy contextually. Important here is how we conceptualise 'Northern' and 'Southern'. Rather than seeing these in terms of geographical location, we identify as 'Northern' those CSOs (often Northern-based) that have direct access to substantial, mostly Northern-based funding and commonly act as 'fundermediaries', distributing funding to other CSOs, (many of which located in the geographical South) and steering much of their work. By our focus on complementarity, we seek to move away from the linear 'North-South' relations that have dominated debates on CSO collaboration, and offer another angle that does more justice to the multiplicity of CSO relations. A starting point for the present study is that CSOs choose from a wide range of collaboration possibilities and assign varying roles to different collaborations. They often engage simultaneously with multiple CSOs and donors. Collaboration takes place at multiple levels, and international-level collaboration does not necessarily have the prime importance it is frequently given in development studies work on advocacy collaboration. Exploring complementarities from this perspective allows us to identify a wide range of forms, rooted in real-life understandings of added value that CSOs may identify. In particular, it allows us to learn to what extent the standard set-up of advocacy collaborations funded from the global North as international partnerships with NorthSouth 'partnerships' as the key relation, is valid from the perspective of Southern partners. We raise this question in particular given that CSOs' orientations are often likely to be largely domestic (Sriskandarajah and Tiwana 2014) and may be construed independently from roles formally assigned to them through aid chains (Elbers 2012).

Our investigation of these issues was guided by the following question: What complementarities do CSOs working on DRR in India identify between themselves and other CSOs? We begin by exploring complementarity through a case, before considering potential wider implications for broader CSO collaborations. In the following sections, we explore complementarity as a new way of approaching CSO collaboration in advocacy. Subsequently, we discuss key dimensions of civil society that show the pertinence of examining complementarity in CSO advocacy collaborations: diversity, Southern ownership and leadership. We then present the case, site and study methods, before describing the findings, including our typology of forms of complementarity among CSOs involved in DRR and results on the perceived role of international CSOs. We present this typology as a proof of principle, validating and illustrating the starting points we set out in the theoretical sections. Finally, we reflect on our findings' broader significance.

\section{Complementarity}

Complementarity is commonly acknowledged as important in multi-stakeholder collaborations ranging from business (see, e.g. Gyrd-Jones and Kornum 2013) to governance (see, e.g. Coston 1998, Mbzibain, and Ongolo 2019). Analyses of complementarity commonly emphasise comparative advantage as a main starting point as well as the context-dependent nature and often at least partly emergent quality of complementarity resulting from interactions over time. We also find emphasis on mutual respect and autonomy of the actors involved (Coston 1998; Najam 2000; Mbzibain and Ongolo 2019). Studies that go into complementarity in advocacy collaborations address structural aspects rather than contingencies and relational dynamics. They have usually been limited in scope, emphasising complementarity between the contributions of Northern and Southern CSOs in collective advocacy efforts. Although Northern CSOs' control over financial resources is a major source of power imbalance, added 
value in collaboration is commonly understood as mutual, creating a situation of interdependence (O'Brien and Evans 2016). Northern CSOs offer funding, specialised knowledge, and access to political fora and decision-making arenas for Southern partner organisations (Bandy and Smith 2005). Northern CSOs also contribute to Southern CSOs' capacity through interventions such as training and organisational strengthening (Wetterberg et al. 2015). For their part, Southern CSOs contribute crucial information and knowledge 'from the ground' that can be used to build credible cases or appealing testimony for presentation in policy processes in the Northern and international arenas to which Northern CSOs have access (Keck and Sikkink 2014). The knowledge contributed by Southern CSOs also builds legitimacy for Northern CSOs (Pallas and Urpelainen 2013). Combined and coordinated advocacy at national and international levels is a common strategy, creating another form of complementarity in transnational advocacy campaigns (Arensman et al. 2015, 2017).

With its emphasis on international campaigning, which is often led and coordinated by Northern CSOs (Wong 2012; Keck and Sikkink 2014) previous research has engaged with the complementarity of diversity primarily in ways that identify and confirm typical complementarities in North-South CSO collaborations, which tend to centre on coordinated, Northern-dominated campaigning. This previous work could thus only be expected to confirm complementarities of 'expertise', 'local knowledge', access to arenas and financial resources-the common ingredients in transnational CSO campaigns. Existing research has also pointed to complementarities validating international NGOs' capacities, but it remains unclear how important these are to Southern CSOs seeking to follow their own agendas and potentially desiring a domestic advocacy focus. In short, because complementarity has not yet been taken up in the debate on development as a concept that can be used to advance collaboration, it has remained implicit and likely underutilised.

\section{Diversity}

To develop complementarity as a starting point for collaboration, the diversity of civil society would need to be engaged with more and also differently. In governance arrangements, CSOs are often grouped together despite having different worldviews, mandates and operating styles (Hilhorst, Desportes and De Milliano 2019). Similarly, in the 'aid world', civil society is often equated with professional, formal organisations, although it is actually much broader. Some previous work has indirectly addressed the inattention to diversity in civil society. For example, research on the 'NGOisation' of civil society to fit donor requirements (Lang 2013) has examined how this organisational form advances at the expense of others. At the same time, it is not the case that nothing is known about diversity in civil society. A large body of research differentiates between, for instance, informal movements and formal organisations (Sika 2018), autonomous and party/government-affiliated CSOs (Ray 2000), or grassroots/member-based and professional NGOs (Mercer 2002). Going beyond these commonly explored and often binary distinctions in organisational type, others have identified specific dimensions of diversity, such as resource disparities, perceptual and identity differences, and action repertoire preferences, as well as differences in perspectives and opinions (Magis 2010, p. 320; Sahoo 2013; Shah 2016). However, in governance and aid, these diversities are not truly engaged with.

Considerations of diversity in existing work on CSO advocacy collaborations have been more substantial, but at the same time limited in scope, again not engaging the above diversities in their own right (Van Wessel et al. 2018). This work is often focused on transnational campaigning and mostly engages diversity as it emerges on this front. In some cases, this may be as a barrier to developing common ground (Magis 2010) or coordinated campaigning (Wong 2012). Other work points out that diversity as a reality gets 'black-boxed' by assumptions of shared values and discourses (Jordan and Van Tuijl 2000). Some more critical work points out how 'global' (Northern-dominated) discourses have pushed out alternative discourses originating in the global South (Bownas 2017). When diversity is valued, it is for its potential contribution to attaining a shared purpose through collaboration based on the foundation of common ground. Magis (2010) has demonstrated that coalitions value the strength diversity brings through providing access to a broad range of resources and audiences and facilitating comprehensive understandings ( $\mathrm{p}$. 325). Discussing the ability to pursue both joint and organisational goals through collective action, Saz-Carranza and Ospina (2011) argued that it is crucial for a network to value diversity as the 'power base' that provides credibility and legitimacy, while the network develops the power to act collectively and translate this diversity into access and action. They identified a unity-diversity paradox in collaborative action for collective goals. Although network diversity and unity are both necessary to achieve these goals, they may also undermine each other, as giving space to diversity can pre-empt the unity needed for coordinated action, while imposition or creation of unity can push valuable diversities to the background (Saz-Carranza and Ospina 2011, as cited in Arensman, van Wessel and Hilhorst 2017, p. 1313).

In studies of collaboration, diversity has thus mainly been treated as both a resource and a barrier for collective 
action. Although this approach relates well to questions around diversity and collaboration in the context of transnational campaigns, its value for understanding the role of diversity in collaboration more broadly is uncertain. Collaboration in advocacy does not necessarily seek to attain collective goals through joint campaigning; it can also aim to advance the goals of individual organisations, and it may involve exchanges and actions that do not demand shared understandings or collective coordination (Arensman et al. 2017). Finally, the emphasis on collective understandings distracts from the complexity of issues that demand diverse capacities, perspectives and representation of diverse stakeholders (Dentoni et al. 2018).

In this study we engage the diversities CSO staff themselves identify as relevant, to see how this relevance emerges for CSOs trying to attain objectives in the domain of DRR, so that such diversities may be acknowledged and engaged with more. The context of India lends itself well to an exploration of the significance of such diversity. Civil society in India serves many types of constituents and comprises many organisational forms, agendas and types of relations between actors (Van Wessel et al. 2018), also when it comes to DRR (Pal and Shaw 2018; Van Wessel et al. 2019). DRR is a complex issue and is also approached as such in the Indian context (Pal and Shaw 2018). CSOs in this context seeking collaboration may therefore be expected to approach collaboration with other CSOs with an eye to variegated capacities, understandings, viewpoints, and forms of power and legitimacy. We can also expect CSOs' roles to take shape in interaction with other CSOs, as they position themselves in relation to each other and exchange resources considered valuable for their own or more collective objectives, with at least some engagement with the diversities involved.

\section{Southern Ownership and Leadership}

Worldwide, there is growing recognition among CSOs, multilateral institutions and donor states of the necessity of 'Southern' ownership in sustainable development. The dominance of Northern CSOs and donors in many NorthSouth collaborations has been widely established and problematised, mainly pointing to the detrimental effects of donor dependence and associated impositions on autonomous roles (see, e.g. De Almagro 2018; Jalali 2013). A long-term goal increasingly embraced by academics, donors and sections of civil society is to create conditions where responsibilities and leadership increasingly lie with Southern CSOs (see, e.g. Banks et al. 2015; Netherlands Ministry of Foreign Affairs 2019; Global Fund Community Foundations n.d.; Goodman 2016). Solutions proposed thus far focus fully on these same North-South power relations.
Some do so in material terms, seeking a solution in direct funding (Ismail 2019). Other solutions on offer seek to reshape working relations. Mostly this is framed in terms of 'partnership', a concept that has itself already been frequently problematised (Fowler 2016; Contu and Girei 2014; Elbers 2012). A more facilitating role for Northern actors is also argued for (Banks et al. 2015). Other ways forward are seen in the reclaiming (Mitlin et al. 2007) and resistance (Townsend et al. 2004) through which Southern CSOs carve out space for alternatives, withstanding domesticating mechanisms in the aid system. The current \#Shifthepower movement that seeks to advance local groups' independence and ownership is also part of this struggle for independence.

While these are important efforts seeking to tackle detrimental effects of power relations between Northern and Southern CSOs, our study seeks move away from North-South power relations as the key problem that needs to be fixed. Rather, we question the prominence of the North-South binary relation structuring collaborations in development and point to the importance of more Southern-centred collaboration dynamics. If Southern CSOs are to do more leading, their contexts, understandings, capacities and ambitions must move more to the centre in programmes and therefore also in collaborations. We need to learn who matters to Southern CSOs, for what, from their own understandings of what they are trying to do and achieve. This can advance Southern ownership and leadership in several interconnected ways. First, this makes the true identities and aims of Southern CSOs more visible, facilitating their recognition. This counters the common practice among Northern CSOs to brand their programmes and results in terms that privilege collective aims and understandings that are often largely Northern-defined, with little eye for the specific perspectives that Southern CSOs bring into the collaboration. Secondly, understanding Southern perspectives on advocacy collaboration can help donors and Northern CSOs establish what Southern leadership would mean in practice for questions regarding with whom and for what to work, how to collaborate and what this implies for various actors' roles. CSOs navigate the possibilities of their roles as agents and construct- these roles based on their own perspectives and capacities while engaging with opportunities and constraints within the contexts relevant to them (Van Wessel et al. 2019). Recognising this may have important implications for CSOs' roles in collaborations, as it makes it possible to identify how different collaborations may or may not strengthen Southern CSOs' roles, from their perspective. For example, the prominent nature and added value of donors' and Northern CSOs' involvement often envisioned in development programmes cannot be taken as given (Van Wessel et al. 2019). Finally, the 'collective' goals of 
coalitions, alliances and partnerships may not actually be so collective when we foreground individual organisations' objectives or emergent objectives by focusing on how CSO leaders think about the helpfulness of collaborations. Focusing on Southern CSOs' perspectives on advocacy collaborations may also reveal the relative importance of international vs. national-level advocacy efforts and give more prominence to domestic efforts in which Southern CSOs can have a more leading role. As Gaventa and McGee (2010) have shown, country-level advocacy and policy change are important, and this is increasingly understood in the development sector (see, e.g. Walker and Christie 2015). Importantly, this does not mean ignoring the power that often structures these relations, but rather finding a way to shed light on the relative added value of CSOs for achieving organisational and collective objectives. Exploring complementarity in shaping collaborations can thus help the development sector and individual CSOs to identify CSOs' different qualities, capacities and resources and to consider these in collaborations to advance ownership and Southern leadership. The often difficult and sometimes stifling search for 'common ground' can then give more way to emergent, fluid and smaller-scale ways of finding each other.

\section{Case, Site and Methods}

Disasters such as floods, landslides and droughts affect human lives, agriculture, infrastructure and other physical assets. Disasters, hazards and vulnerability are inter-related through correlations between natural resource management, poverty and social inequality (Blaikie et al. 1994; Hewitt 2014). In disaster contexts, the social, cultural and economic environments of socially disadvantaged groups are the most affected (Blaikie et al. 1994; Benson et al. 2001). The highest levels of disaster resilience are found in societies with varied economies, robust institutions, cohesive social infrastructure and all-encompassing policy agendas to prevent or deal with the impact of disaster (Noy 2009, Aldrich and Sawada 2015; Dagli and Ferrarini 2019). In recent years, DRR has increasingly become a policy priority among states, international institutions and CSOs. The United Nations Office for DRR (UNISDR 2004) defines DRR as 'the systematic development and application of policies, strategies and practices to minimise vulnerabilities, hazards and the unfolding of disaster impacts throughout a society, in the broad context of sustainable development' (p. 3). Policies and strategies in the multidisciplinary field of DRR approach disasters as having socioeconomic, political and environmental origins (Hewitt 2007; Wisner et al. 2004; Gaillard 2007; Alexander 2000). This is reflected in multiple global narratives and frameworks, such as the Sustainable Development Goals 2015-2030 (UN 2015a), the Sendai Framework for Disaster Risk Reduction (UN 2015b), the Framework Convention on Climate Change-Conferences of the Parties (UN 2015c) and the World Humanitarian Summit (UN 2016). Effective DRR makes communities resilient, guaranteeing that vulnerability will not be amplified through development efforts or other externally initiated activities (UNDP 2004; UNISDR 2004; DFID 2005).

Vulnerability is not inevitable-DRR measures can minimise the physical and human consequences of disasters. Nevertheless, governments cannot accomplish substantial, sustainable DRR alone. It is necessary for different kinds of CSOs to play a role in these efforts (OECD-DAC 1994; Vaughan and Hillier 2019). Recent experiences in Asia suggest that CSOs have been key in supporting local governments' capacity building (Khan and Ali 2014). UNSIDR acknowledges the special competences of CSOs operating at grassroots level, which can respond to local people's priorities and build on local capacities. Relatively free from bureaucratic structures and systems, CSOs are comparatively flexible, and they are often able to address the needs of the poorest and most vulnerable (UNISDR 2006 , p. 2). Compared with other actors, CSOs are thus well positioned to adopt inclusive and consensual approaches in local disaster planning and resilience building (Lassa 2018). The Sendai Framework for Disaster Risk Reduction 2030, a leading global framework, recognises the potential role of CSOs in DRR worldwide. Existing studies suggest that the scope of CSOs' work can still expand in terms of humanitarian and international development for DRR in both emergency and non-emergency contexts, especially where empty spaces are left by formally mandated institutions such as local and national governments (Lassa 2018).

India is prone to multiple disasters and natural hazards, which have the largest effect on vulnerable populations (Dilley et al. 2005; Ray-Bennett 2009). Disaster management in India has grown from a relief-based approach to a multidimensional and proactive institutionalised set-up involving multiple stakeholders (MoEF 2012). In many cases these include CSOs (see, e.g. Chatterjee et al. 2010; Vahanvati and Mulligan 2017; Pal and Shaw 2018). Roles that the state assigns to CSOs seem to be primarily in support in capacity development, awareness raising, mobilisation, relief, reconstruction and rehabilitation, i.e. complementing the capacity of the state (National Disaster Management Authority 2016; Bahadur et al. 2016; Pal and Shaw 2018). While this underscores complementarity between CSOs from the (instrumental) Indian state's perspective, it does not do so explicitly, nor does this literature engage with CSOs' perspectives on complementarity between them. To explore this complementarity between 
CSOs from their perspectives, we engaged with 11 CSOs, most of which were members of a single consortium of professional CSOs working on DRR and related themes across India. This consortium, in turn, was part of an international collaboration of CSOs working on DRR advocacy. This collaboration spanned multiple continents and was officially led by a Netherlands-based alliance of CSOs supported by the Netherlands Ministry of Foreign Affairs. We chose to engage with this consortium since it would allow us to research a case of diverse CSOs involved in DRR collaboration involving both domestic and international CSOs. While our sample may not be representative of the population of CSOs working on DRR (e.g. involving mostly professional organisations, and engaged in collaboration), our sample did guarantee that we would obtain meaningful information about how CSOs working on DRR in India perceive the nature and value of diversity in collaboration. In addition, we did not focus on the consortium but also explored CSOs' ideas about collaboration more broadly. Another study members of our team conducted (Katyaini et al. n.d.) confirmed collaboration across diversities also with another set of CSOs.

The CSOs in our sample were diverse in terms of organisational background and included humanitarian, faith-based, secular, technical, rights-based and development organisations. Some were Indian chapters of international CSOs, others were state-level or national-level Indian CSOs and one was a network of small, informal grassroots CSO. They worked at different levels, from the grassroots to state or national levels. They also differed widely in topical focus, with DRR in many cases integrated in a wider range of activities including disaster management more broadly, environmental and natural resource management, climate change adaptation/mitigation and inclusive development. We explored complementarity both inside and outside the consortium because many of the CSOs had experience with other collaborations. However, we will likely not have covered the full spectrum of possibly relevant diversities with our sample, for example because we had few social movement organisations in it. This, however, does not detract from the validity of our proof of principle.

We conducted 33 interviews with staff members (mostly directors and project managers) working for these CSOs. These interviews focused on complementarity, asking about their preferences for collaboration partners, the ways different types of CSOs complement each other, and the added value of different CSOs in a collaboration. We also examined the CSOs' internal documents and websites, attended their internal meetings and workshops, and visited project implementation field sites. Data analysis consisted of finding patterns in the interview data with regard to complementarity, through several rounds of inductive coding and identifying different forms of complementarity that we categorised into types. We used ATLAS.ti software for coding the data. Such construction of typologies regarding CSO roles through data such as staff interviews is more commonly done (see, e.g. Sunata and Tosun 2019).

\section{Findings}

In this section, we discuss the typology we developed, which describes complementarities in terms of capacities, geographical landscape, perspectives, networks and levels. Table 1 provides an overview of complementarities we identified, also indicating the specific expressions. Below, we explain and illustrate these.

\section{Complementarity of Capacities}

Three aspects of complementarity of capacities emerged in the research: knowledge transfer and training, community mobilisation, and resource mobilisation.

\section{Knowledge Transfer and Training}

Knowledge exchange and complementary knowledges in collaboration were frequently emphasised. First, considering the multidimensionality of disaster and DRR, different CSOs having expertise in different DRR-relevant domains were often pointed to for their complementarity. 'If we have to work in Uttarkhand, we cannot do it by ourselves, we need [local partner] as they know the topography and the needs of the people and the terrain better', as one interviewee working on inclusiveness of DRR explained. Second, interviewees also commonly emphasised how collaborations had led to important learning that helped them develop and/or execute interventions in DRR. As interviewee from a CSO specialising in housing explained: 'from [CSO specializing in ecosystems management] we have learnt that DRR is also about this. In the future, because of climate change, it is important to work on ecosystems management'. Third, many of the interviewed CSO staff considered people's problems to be localised, requiring context-specific expertise and knowledge, requiring complementarity in capacity between local CSOs. For example, a national-level technical organisation emphasised that local CSOs have the ability to train other grassroots-level CSOs on building disaster-resistant houses in areas with earthquakes, floods or landslides, using local materials, arguing that local CSOs are sensitive to local communities' needs and are more aware of the topography. Other CSOs pointed out that grassroots- and state-level CSOs have a better understanding of the locally rooted social dynamics of gender, caste, religion, ethnicity or 
Table 1 Overview of complementarities

\begin{tabular}{|c|c|c|c|}
\hline $\begin{array}{l}\text { Complementarity of capacities at } \\
\text { domestic level }\end{array}$ & $\begin{array}{l}\text { Knowledge transfer and } \\
\text { training }\end{array}$ & Community mobilisation & Resource mobilisation \\
\hline $\begin{array}{l}\text { Complementarity within a geographical } \\
\text { setting/landscape at domestic level }\end{array}$ & In territorial terms & Complementary specialisations & \\
\hline $\begin{array}{l}\text { Complementarity of perspectives at } \\
\text { domestic level }\end{array}$ & $\begin{array}{l}\text { In terms of the diverse } \\
\text { ideological approaches }\end{array}$ & & \\
\hline $\begin{array}{l}\text { Complementarity of networks at } \\
\text { different level }\end{array}$ & Funding & Knowledge & Advocacy \\
\hline $\begin{array}{l}\text { Complementarity of advocacy at } \\
\text { different levels }\end{array}$ & $\begin{array}{l}\text { Local-level advocacy } \\
\text { complements state-level } \\
\text { advocacy }\end{array}$ & $\begin{array}{l}\text { State-level advocacy } \\
\text { complements national-level } \\
\text { advocacy }\end{array}$ & $\begin{array}{l}\text { National-level advocacy } \\
\text { complements international-level } \\
\text { advocacy }\end{array}$ \\
\hline $\begin{array}{l}\text { The complementarity of international } \\
\text { CSOs }\end{array}$ & $\begin{array}{l}\text { By association: visibility, } \\
\text { credibility and prestige }\end{array}$ & $\begin{array}{l}\text { New knowledge, approaches } \\
\text { and professional practices }\end{array}$ & $\begin{array}{l}\text { Funding towards a longer-term } \\
\text { vision }\end{array}$ \\
\hline
\end{tabular}

conflict, allowing CSOs specialising in different aspects of knowledge to build on each other's capacities in local collaboration. Knowledge regarding the local socio-political context and administration was also important. The director of a grassroots CSO noted that "coordination between the village, block and district level administration is necessary for the project to run well'.

\section{Community Mobilisation}

Most of the studied CSOs worked in grassroots networks operating through village-level volunteers, field staff and offices. Through these networks, CSOs mobilised the population, spread information and created awareness. Most such networks were led by secular organisations, but some were religious. For example, an international Christian humanitarian CSO had a wide network throughout India, including 174 church-affiliated social service organisations at the village, district and state levels in Bihar, Gujarat, Uttarakhand, Odisha and Tamil Nadu. These states are prone to floods, earthquakes, landslides, cyclones, and tsunamis. To address the associated problems, the organisation collaborated with other CSOs in the region. It also used its network to mobilise people and spread knowledge produced by other international and national CSOs. For instance, the organisation's DRR project manager noted that they previously had little knowledge on wetlands and ecosystem management but learned about water-body management and wetlands preservation through collaboration with an international CSO. They then spread this information to communities in their reach. This shows how complementarity can facilitate CSO efforts to spread awareness in local communities on the importance of reducing disaster risk and create capacity and motivation to act.

\section{Resource Mobilisation}

Resource mobilisation is important for CSOs. Some organisations are very successful in this, whereas others struggle significantly, and some international organisations provide resource mobilisation training. For example, a senior project manager of the Indian chapter of an international Christian CSO reported receiving training from their international partners on fundraising and on developing a database of DRR funding sources. Through collaboration, national-level CSOs also assist grassroots-level CSOs with resource mobilisation, sharing information and teaching them how to apply for funds from government schemes or the local administration.

\section{Complementarity Within a Geographical Setting}

This complementarity concerns the added value of CSOs working in the same geographical area. One form is territorial. CSOs working in a particular geographical environment are familiar with the region's topography, giving them an advantage in understanding the local landscape, water bodies, agricultural practices, climatic and soil quality, as well as social aspects like local gender and caste dimensions. CSOs working on DRR at various levels within the same area can complement each other's work through partnerships. Furthermore, an intervention in one location can impact other nearby locations, as a senior project manager of an environmental technical CSO explained:

In DRR, we speak about planning beyond administrative boundaries of village or gram panchayat [local governance unit]. The focus is on the landscape. Thus, activities in one village may influence other villages. For example, an upper catchment village may cause waterlogging in another village. In order 
to have an effect in the lower-lying village, some activities may be needed in the upper village, perhaps in the form of change in agriculture practices or cropping patterns. We have to plan for the lower catchment areas for risk reduction and need to involve the areas of the upper catchment locations and the CSOs working there.

Complementarity within a geographical setting can also involve multiple types of knowledge. In a specific setting, CSOs work on a variety of issues and produce information on themes such as climate change adaptation, ecosystem management, animal husbandry, livelihood and agricultural diversification, health and sanitation, and child safety. These diverse specialisations strengthen collaborations among CSOs working in the same geographical area. In CSO training programmes, organisations with different specialisations come together to solve problems. For example, during training sessions on flood mitigation organised by the studied consortium, some CSOs provided training on how to build safe shelters and on early evacuation techniques, whereas others emphasised health issues and discussed first aid.

\section{Complementarity of Perspectives}

Complementarity of perspectives refers to the diverse ideological approaches CSOs follow. Each CSO in our study viewed DRR through a different lens-social, humanitarian, rights-based, or environmental. For example, an international Christian CSO in our study approached disaster from a humanitarian perspective; a technical environmental CSO from a standpoint of ecosystem management, climate change and landscape; and a rights-based CSO from the perspective of the marginalised communities and inclusiveness in development. The country director of an international technical CSO explained:

We see DRR from an environmental and ecosystems perspective; we take into consideration the metrological data, the pattern of floods and science to prevent future disaster related risk.

While the director of a rights-based CSO emphasised other dimensions:

When disaster happens, animal welfare and rights should be taken into account as well, apart from human life. Animals must be identified, so they can be easily reunited with their owners after the disaster and similarly sharing information on effective vaccination programmes to protect animals' health as a preparation before disaster strikes.
In CSO collaborations, these different perspectives can combine to make it possible to address DRR in a more complete and inclusive way. Although these differences sometimes lead to competition, they can also be integrated, and some of the studied CSOs saw the different perspectives in the consortium as enlightening.

\section{Complementarity of Networks}

CSOs can facilitate each other's access to diverse national and international platforms, centring on important shared interests (i.e. funding, knowledge and advocacy). CSO networks provide opportunities and can facilitate the voices of CSOs being heard in different arenas. Most of the interviewed CSO staff agreed that being part of varied networks develops complementary collaborations among CSOs. Although there may sometimes be competition for funds, networks are often enabling in nature, directly or indirectly facilitating information sharing on funding and other vital issues. This is especially helpful for small CSOs, which would not otherwise have access to such information. One relevant DRR platform is SPHERE India, the Indian chapter of a global movement aiming to improve the quality of humanitarian assistance that began in 1997. Another network is Building Advisory Services and Information Network-South Asia, a regional knowledge platform that provides information and shares knowledge on rural habitat and livelihood solutions in South Asia. The interviewed CSO staff noted that being part of international and national forums not only helps in getting funds, recognition and credibility, but also provides the opportunity to collaborate with like-minded CSOs and articulate voices. Furthermore, it has facilitated synergies between international trends and their adaptation to country contexts. Examples of such developments include the Sendai Framework for DRR (2015-2030), the Hyogo Framework (2005-2015), the World Conference on DRR, and the Asian Ministerial Conference on DRR.

Additionally, some CSOs have access to the state, working closely with the government and serving as members of government-appointed committees and panels on DRR. This access is possible because of their credibility and track records. One of the studied CSOs had access to DRR policy makers, and from that position could bring in viewpoints of other CSOs it was working with, which had less direct access and act as the voice of these partner CSOs, to a degree. In addition, for some Indian CSOs, being associated with reputed national and international CSOs that work with the Indian government adds to their own credibility in the eyes of Indian government agencies, and thus their access. 'Due to our association with [international $\mathrm{CSO}$ ] we were able to engage [government agency], as one interviewee explained. 


\section{Complementarity of Advocacy at Different Levels}

Advocacy takes place at subnational, national and international levels, and collaboration among different CSOs facilitates spreading their messages across these levels of influence.

\section{Local-Level Advocacy Complements State-Level Advocacy}

Local CSOs provide contextually rooted perspectives, ideas and case studies. Being rooted at the local level gives them a good understanding of communities and their issues. Context-specific knowledge of socially embedded inequalities related to caste, class, gender and religion is useful in formulating DRR policies. As a programme manager of a grassroots humanitarian and rights-based CSO noted, policy advocacy requires bringing issues that are local in nature into the public domain. Context-specific aspects are especially important when government officials and policy makers formulate plans for village development or district-related DRR. Although local-level grassroots CSOs may not have direct access to the state administration, their collaboration with larger CSOs working at the state level gives representation to their perspectives in this arena. An interview with the director of a state-level rightsbased CSO illustrated this point:

The state administration wanted to have a state-level rehabilitation policy [...] to develop [housing] colonies and shift local communities when there is a disaster. We were asked to provide policy suggestions. We partnered with locally relevant, diverse grassroots CSOs for interventions and approached them for opinions on this issue. They informed us that shifting local communities to a semi-urban colony would bring trauma, alienation and loss of livelihood. Thus, we put the views of the grassroots CSOs before the state administration and advocated for policy change.

\section{State-Level Advocacy Complements National-Level Advocacy}

CSOs working at the state level seek to represent statespecific experiences and findings at the national level. They advocate for the inclusion of state-specific demands in DRR policies. A senior manager of a rights-based, technical development organisation noted that state-level CSOs can provide information to each other and to national-level CSOs, offering state perspectives. Because of their work in particular states, some CSOs are often invited to advise the government during policy formulation. These CSOs take this as an opportunity to present their viewpoints and those of other state-level CSOs with which they collaborate that would otherwise lack access to such national platforms.

\section{National-Level Advocacy Complements International- Level Advocacy}

Through country-specific examples and case studies, national-level CSOs advocate for India in international platforms. For example, national-level Indian CSOs brought country-specific concerns to the South Asian Association for Regional Cooperation's initiative for a community-based trans-boundary early warning system. An interview with the head of a secular humanitarian CSO illustrates a national-level CSOs' advocacy work in international contexts:

Whenever floods happen, they see no boundaries, leading to huge loss of human and animal life and financial damages. We advocate for development of community-based early warning systems involving CSOs, local communities and administrations, and research institutes. India is to have a bigger role because of it regional geo-political importance and its high stakes in it. We try to make sure that international CSOs doing advocacy on this take the Indian stance forward.

\section{The Complementarity of International CSOs}

Most of the complementarities CSOs discussed are at the domestic level. Where does that leave international CSOs collaborating with these domestic CSOs? The staff of Indian CSOs we interviewed largely defined this complementarity in terms of support and facilitation: strengthening domestic CSOs through their capacities and contributions. First, the Indian CSO staff valued being associated with international CSOs. Many felt that collaboration with international CSOs increases their visibility, credibility and prestige in domestic NGO circles or government circles. As a former deputy manager of a domestic rights-based CSO noted:

Our prestige is enhanced and other domestic CSOs take us seriously when we liaise with global CSOs. At times, meetings with policy makers can be organised in an effective manner when foreign names are attached.

Similarly, participation at international fora can be helpful at the domestic level. As one CSO explained: 'if your work is showcased in an international forum through partnerships and collaborations, the state might think of taking up some of your ideas in their policy'. Association 
with international CSOs thus appears to expand for Indian CSOs their mandate in their domestic contexts in the eyes of important stakeholders, including the state. This was a common point among interviewees, in spite of the sensitivities around foreign collaborations that have gained prominence in recent years in India, which apparently has not affected this complementarity in a major way in the context of DRR. At the same time, however, some interviewees did mention avoiding association with (international) CSOs having a reputation for confronting the state, such as Greenpeace, or even some Christian development organisations, in light of the growing dominance of Hindu nationalism in India.

For some interviewees, association with international CSOs also helps gain recognition internationally, e.g. with foreign funders who may classify a CSO in terms of, e.g. capacity and values because of its association with international CSOs or networks.

A second complementarity lies in the exposure to international frameworks and ideas that engagement with international CSOs offer. Through international collaboration, Indian CSOs get to be exposed to new and globally current ideas and developments, such as the Sendai framework. This again helps these CSOs domestically, given the status of such frameworks as well as the pressure or ambition of the Indian state to relate to such frameworks. As one interviewee explained:

Global partnerships really help. A global mandate is necessary to highlight an issue. With a global mandate and global events, you can do anything you want, with its backing. A mandate has to be rationalised. For example, the Sendai framework provides a mandate for disaster governance.

Relatedly, interviewees mentioned the added value of international CSOs' knowledge and expertise, exposing them to new knowledge, approaches and professional practices.

A third type of complementarity offered by international CSOs involves international CSOs' ability to provide funding towards a longer-term vision, rather than the shortterm visible results often demanded by domestic funders such companies supporting NGOs through India's mandated corporate social responsibility spending (the Companies Act of 2013). One interviewee noted that, compared with domestic donors, international CSOs are sometimes more open to experimentation and risk-taking in terms of achieving results. These characteristics of international CSOs as donors were appreciated. As the director of a national-level technical and environmental CSO described:

It is easy to convince the international donors about new ideas, as they are more willing to experiment and take risks. In contrast, domestic donors do not see relevance in many new ideas [and are not] ready to take risks; they prefer service delivery outputs [and] have a short-term vision.

Another interviewee found international CSOs to be open and patient in supporting gradual change. As the head of a state-level technical CSO said, 'Awareness, teaching and empowerment all need time to develop, so they are willing to see changes that are slow and gradual'. Several interviewees, however, also pointed to constraining elements in relations with international CSOs. The director of a national-level technical CSO complained of not getting credit to Indian CSOs as actors in their own right:

Our name or any of the other domestic CSOs' name is not mentioned in their documents. We are kept anonymous. This is worrying for us. We need acknowledgment of our work when we collaborate in an international project. It looks a bit colonial.

Some Indian CSO staff described the role accorded to them by international CSOs as that of a subcontractor, carrying out tasks rather than developing their own capacities, innovating or covering their overhead costs. In addition, they described transparency regarding funding allocation across organisations as lacking. This relationship was thus at least in some interviews described not as one between equal partners but rather appeared to be structured to reinforce inequality.

Indian CSOs receiving international funds or collaborating with international CSOs also experienced close monitoring of their work by the Indian state. They found it necessary to carefully select their partners because working with certain organisations could cause problems for the Indian CSOs.

Overall, our findings show that Indian CSOs value collaboration with international CSOs to the extent that these organisations can help them attain their own established objectives, and they express reservations concerning difficulties when collaborations fail to do this. There was very little discussion of complementarity in terms of collective action on 'global' issues or the grand need for 'common ground' and collective endeavour. Although the interviewees were clearly aware of the global nature of issues and were open to internationally developed approaches, seeing their relevance, their conceptualisation of their role and complementarity with international CSOs in executing that role was largely domestically oriented. 


\section{Discussion and Conclusion}

The typology of complementarities as shown in Table 1 and the discussion above shed lights on the way CSOs working in DRR emphasise complementarities at domestic level, putting value on the diversities of civil society in their own context, with international CSOs' complementarity largely defined in terms of support and facilitation. The findings are context-specific and likely idiosyncratic in terms of the exact nature of the complementarities. However, the broader insight of the relative roles of domestic and international complementarities point for us to broader implications of the analysis, providing three main insights.

The first insight concerns acknowledgement of diversities as a starting point for developing collaboration. The interviewed CSO leaders pointed to the value of complementary among CSOs across a range of aspects: capacities, geographic settings, perspectives, networks and levels. Organisations identified these complementarities from a clear understanding of their own roles and identities. In describing the complementarities, CSOs emphasised the added value of collaboration rather than a redefinition of roles through collaboration. Whereas CSO programmes often stress a common purpose and common ground among partners, the CSO staff we interviewed emphasised complementarities relevant for attaining their individual organisational objectives. Although this may suggest a lack of coordination, it fits with understandings common in the governance literature, where collaboration between stakeholders and organisations is usually assumed to be necessary because their different perspectives, interests and bodies of knowledge may all contribute to solving a problem-something Northern-dominated programming generally does not pay much explicit attention to (see, e.g. Sida 2019: Netherlands Ministry of Foreign Affairs 2019). The interviewed CSO leaders commonly acknowledged that a complex, multidimensional issue such as DRR implies interdependence among the involved CSOs. Arguably, openness to complementarities as they emerge contextually may facilitate the integration of work on multiple dimensions of an issue in ways that would be difficult to achieve through 'coordinated' efforts following a set agenda rooted in the understanding of a few leading CSOs responsible for a formalised and commonly fundingbased 'partnership' that may involve much central steering. Although our findings suggest this potential, in practice, many CSOs do work with funders with specific agendas and an inclination to control and 'coordinate'. Dominant $\mathrm{CSO}$ and donor practices may limit the emergence of the types of complementarity that the CSO staff suggested would be useful.
There may be important differences between what CSOs identify as complementarities and actual patterns of organisational behaviour. Competition, transaction costs, diverging understandings and other barriers (Schmitz et al. 2018) may work against both the optimal exploitation of complementarities and collaboration in general. It is nevertheless important to explore the possibilities. Acknowledgement of diversity in early stages of programme development and openness to emergence in the course of programmes can help to do justice to the identities, capacities and aims of the CSOs involved, thereby advancing Southern leadership and ownership in collaborations. A next step may be developing principles and practices for shaping and adapting programming that allow complementarities to be realised.

The second insight from this study concerns contextuality, pertinent to the question of Southern ownership. The findings primarily bring out context-specific, contingent and emergent qualities of complementarities that may come about when interactions are rooted in mutual respect and autonomy. As the data analysis shows, complementarity is in fact already a reality for CSOs, which have a good understanding of who can matter to them, for what and why. Many complementarities identified by the interviewees involved other CSOs working in the Indian context, directly relevant to their objectives. Our data also show then, that complementarity is not necessarily or only about building on Southern capacity. It is also about acknowledging and starting from Southern CSOs' understandings of who matters for what when working on an issue. International complementarities matter (e.g. for funding, knowledge sharing, capacity development, and spreading values and norms), but the Indian CSOs were geared towards addressing what they saw as domestic problems (cf. Pallas and Urpelainen 2013) and usually focused on domestic complementarities. These domestic complementarities could be either context-specific (e.g. expertise on vulnerabilities rooted in local social inequalities or climatic conditions) or generic (e.g. project management). This implies that it may be worthwhile to explore complementarity as a foundation for international advocacy collaborations that are more open to Southern perspectives. Openness to this from donors and Northern CSOs may lead to putting in perspective the role of 'international dimensions' as defining issues and to seeing the importance of domestic issues and domestic-level collaboration. From a Southern CSO's perspective, 'local knowledge' and 'from the ground' may mean knowledge that is important for domestic advocacy and that prioritises contextually significant issues (e.g. caste discrimination) that are not necessarily central in international discourse. Important 'expertise', even for generic capacities like project management, may be locally available rather than 
exclusive to international NGOs. In setting up CSO advocacy programmes, acknowledging this can mean giving contextuality more space and developing argumentation on how the relative strengths of different Southern and Northern CSOs can complement each other in various political arenas (cf. Jordan and Van Tuijl 2000).

The third insight is that it is important to recognise overlapping networks where different forms of complementarity can emerge. In addition to helping to do more justice to Southern diversity, this approach to complementarity can also encourage Northern CSOs to rethink their roles as complementary to CSOs in the South-as another way of advancing Southern leadership This does not have to marginalise Northern CSOs. Rather, this approach facilitates capitalising on relative strengths and improving these from a starting point of mutual respect. This requires asking new questions: How can we acknowledge and complement different already-existing capacities, perspectives, resources and work at multiple levels? How can we add value to what Southern CSOs are already trying to do? How can international advocacy support causes as Southern CSOs understand them? This may also involve encouraging Southern CSOs to integrate international dimensions into their advocacy for DRR and other global issues. The interviewed CSO staff did not assign international CSOs a leading role in their work, but some considered the backing of an international network and the capacity to draw on international norms important for enhancing local CSOs' legitimacy in their own contexts. International advocacy on DRR appeared not to be high on Indian CSOs' agenda, suggesting that there is room for growth regarding a more international outlook on DRR and DRR advocacy. However, encouraging Southern CSOs to incorporate international perspectives into their work is not the same as presenting these as leading for a 'common' agenda backed by a funding relation.

Acknowledgements We thank the CSOs involved in this study for their kind cooperation. We also thank two anonymous reviewers for their helpful comments, and Jennifer Barrett for editorial support. Funding was provided by NWO-WOTRO (Grant No. W 08.311.104).

Open Access This article is licensed under a Creative Commons Attribution 4.0 International License, which permits use, sharing, adaptation, distribution and reproduction in any medium or format, as long as you give appropriate credit to the original author(s) and the source, provide a link to the Creative Commons licence, and indicate if changes were made. The images or other third party material in this article are included in the article's Creative Commons licence, unless indicated otherwise in a credit line to the material. If material is not included in the article's Creative Commons licence and your intended use is not permitted by statutory regulation or exceeds the permitted use, you will need to obtain permission directly from the copyright holder. To view a copy of this licence, visit http://creativecommons. org/licenses/by/4.0/.

\section{References}

Aldrich, D., \& Sawada, Y. (2015). The physical and social determinants of mortality in the 3.11 Tsunami. Social Science and Medicine, 124, 66-75.

Alexander, D. (2000). Confronting catastrophe. New York: Oxford University Press.

Arensman, B., Barrett, J. B., van Bodegom, A. J., Hilhorst, D., Klaver, D. C., Rasch, E. D., et al. (2015). MFS II Joint Evaluation of International Lobbying and Advocacy. Endline Report. Wageningen: Wageningen University.

Arensman, B., van Wessel, M., \& Hilhorst, D. (2017). Does local ownership bring about effectiveness? The case of a transnational advocacy network. Third World Quarterly, 38, 1310-1326.

Bahadur, A., Lovell, E., \& Pichon, F. (2016). Strengthening disaster risk management in India: A review of five state disaster management plans. http://www.indiaenvironmentportal.org.in/ files/file/Strengthening\%20disaster\%20risk\%20management $\%$ 20in\%20India.pdf. Retrieved December 31, 2019.

Bandy, J., \& Smith, J. (2005). Factors affecting conflict and cooperation in transnational movement networks. Coalitions across borders: Transnational protest and the neoliberal order. Lanham, MD: Rowman and Littlefield.

Banks, N., Hulme, D., \& Edwards, M. (2015). NGOs, states, and donors revisited: Still too close for comfort? World Development, 66, 707-718.

Benson, C., Twigg, T., \& Myers, M. (2001). NGO initiatives in risk reduction: An overview. Disasters, 25, 199-215.

Blaikie, P., Cannon, T., Davis, I., \& Wisner, B. (1994). At risk: Natural hazards, people's vulnerability, and disasters. London: Routledge.

Bob, C. (2007). Dalit rights are human rights: Caste discrimination, international activism, and the construction of a new human rights issue. Human Rights Quarterly, 29(1), 167-193.

Bownas, R. (2017). The upside-down roots of a transnational advocacy network: Applying an 'organisational ecology' approach to the anti-GMO network. Global Networks, 17, $195-211$

Chatterjee, A., Gupta, D., \& Jain, N. (2010). Coordination of disaster response: Potential and challenges from Indian experiences. https://pdfs.semanticscholar.org/6513/2776acce77071355a d30e2b08498504881a1.pdf. Retrieved September 9, 2019.

Contu, A., \& Girei, E. (2014). NGOs management and the value of 'partnerships' for equality in international development: What's in a name? Human Relations, 67(2), 205-232.

Coston, J. M. (1998). A model and typology of government-NGO relationships. Nonprofit and Voluntary Sector Quarterly, 27(3), 358-382.

Dagli, S., \& Ferrarini, B. (2019). The growth impact of disasters in developing Asia. Mandaluyong City: Asian Development Bank.

De Almagro, M. M. (2018). Lost boomerangs, the rebound effect and transnational advocacy networks: A discursive approach to norm diffusion. Review of International Studies, 44(4), 672-693.

Dentoni, D., Bitzer, V., \& Schouten, G. (2018). Harnessing wicked problems in multi-stakeholder partnerships. Journal of Business Ethics, 150(2), 333-356.

Department for International Development (DFID). (2005). Disaster risk reduction: A development concern. London: DFID.

Dilley, M., Chen, R. C., \& Deichmann, U. (2005). Natural disaster hotspots: A global risk analysis. Washington, DC: World Bank.

Elbers, W. J. (2012). The partnership paradox: Principles and practice in North-South NGO relations, Ph.D. thesis Radboud University.

Fowler, A. (2016). Non-governmental development organisations' sustainability, partnership, and resourcing: Futuristic reflections 
on a problematic trialogue. Development in Practice, 26(5), 569-579.

Gaillard, J.-C. (2007). Resilience of traditional societies in facing natural hazards. Disaster Prevention and Management, 16, $522-544$.

Gaventa, J., \& McGee, R. (2010). Introduction: Making change happen - citizen action and national policy reform. In R. Naciri, A. Baviskar, M. D. Layton, A. M. S. Rodriguez, C. A. Fuentes, B. C. Carrete, \& P. Ilkkaracan (Eds.), Citizen action and national policy reform: Making change happen (pp. 1-43). New York: Zed Books Ltd.

Global Fund Community Foundations. (n.d.). Community philantropy and \#Shiftthepower. https://globalfundcommunityfoundations. org/what-we-stand-for/shiftthepower/. Retrieved December 31, 2019.

Goodman, E. S. (2016). Changing advocacy practices in a changing world: an evaluation of Oxfam America's influencing work in a shifting international NGO culture. https://digitalcollections.sit. edu/capstones/2884/. Retrieved April 28, 2020.

Gyrd-Jones, R. I., \& Kornum, N. (2013). Managing the co-created brand: Value and cultural complementarity in online and offline multi-stakeholder ecosystems. Journal of Business Research, 66(9), 1484-1493.

Hewitt, K. (2007). Preventable disasters: Addressing social vulnerability, institutional risk, and civil ethics. Geographische Rundschau, International Edition, 3, 43-52.

Hewitt, K. (2014). Regions of risk: A geographical introduction to disasters. London: Routledge.

Hilhorst, D. (Ed.). (2013). Disaster, conflict and society in crises: Everyday politics of crisis response. Abingdon, UK: Routledge.

Hilhorst, D., Desportes, I., \& de Milliano, C. W. (2019). Humanitarian governance and resilience building: Ethiopia in comparative perspective. Disasters, 43, S109-S131.

Ismail, Z. (2019). Advantages and value of funding NGOs in the global South. https://opendocs.ids.ac.uk/opendocs/handle/20. 500.12413/14392. Retrieved December 30, 2019.

Jalali, R. (2013). Financing empowerment? How foreign aid to Southern NGOs and social movements undermines grass-roots mobilization. Sociology Compass, 7, 55-73.

Jordan, L., \& Van Tuijl, P. (2000). Political responsibility in transnational NGO advocacy. World Development, 28, 2051-2065.

Katyaini, S., Van Wessel, M, and Sahoo, S. (n.d.). How development organizations engage in representation. A closer look using the case of disaster management in India. Unpublished paper.

Keck, M. E., \& Sikkink, K. (2014). Activists beyond borders: Advocacy networks in international politics. Ithaca, NY: Cornell University Press.

Khan, A. N., \& Ali, A. (2014). NGOs and disaster risk reduction in Pakistan. In A. N. Atta-Ur-Rahman, A. N. Khan, \& R. Shaw (Eds.), Disaster risk reduction approaches in Pakistan. Tokyo: Springer.

Lang, S. (2013). NGOs, civil society, and the public sphere. New York: Cambridge University Press.

Lassa, J. A. (2018). Roles of non-government organizations in disaster risk reduction. Oxford Research Encyclopedia of Natural Hazard Science. https://oxfordre.com/naturalha zardscience/view/10.1093/acrefore/9780199389407.001.0001/ acrefore-9780199389407-e-45. Retrieved September 14, 2019.

Magis, K. (2010). Convergence: Finding collective voice in global civil society@. VOLUNTAS: International Journal of Voluntary and Nonprofit Organizations, 21, 317-338.

Mbzibain, A., \& Ongolo, S. (2019). Complementarity, rivalry and substitution in the governance of forests: Learning from independent forest monitoring system in Cameroon. Forest Policy and Economics, 109, 101981.
Mercer, C. (2002). NGOs, civil society and democratization: A critical review of the literature. Progress in Development Studies, 2, 5-22.

Ministry of Environment and Forests (MoEF). (2012). India's second national communication to the United Nations framework convention on climate change. New Delhi: MoEF.

Mitlin, D., Hickey, S., \& Bebbington, A. (2007). Reclaiming development? NGOs and the challenge of alternatives. World Development, 35(10), 1699-1720.

Najam, A. (2000). The four C's of government third SectorGovernment relations. Nonprofit management and leadership, 10(4), 375-396.

National Disaster Management Authority. (2016). National disaster management plan. https:/ndma.gov.in/images/policyplan/ dmplan/National\%20Disaster\%20Management\%20Plan\% 20May\%202016.pdf. Retrieved December 31, 2019.

Netherlands Ministry of Foreign Affairs. (2019). Policy framework for strengthening civil society. Power of voices partnerships. The Hague: Netherlands Ministry of Foreign Affairs.

Noy, I. (2009). The economic consequences of disasters. Journal of Development Economics, 88, 221-231.

O'Brien, N. F., \& Evans, S. K. (2016). Civil society partnerships: Power imbalance and mutual dependence in NGO partnerships. VOLUNTAS: International Journal of Voluntary and Nonprofit Organizations, 28, 1399-1421.

OECD-DAC. (1994). Guidelines for aid agencies on disaster mitigation. Paris: Organisation for Economic Co-operation and Development.

Pal, I., \& Shaw, R. (Eds.). (2018). Disaster risk governance in India and cross cutting issues. Singapore: Springer.

Pallas, C. L., \& Urpelainen, J. (2013). Mission and interests: The strategic formation and function of North-South NGO campaigns. Global Governance, 19, 401-423.

Ray, R. (2000). Fields of protest: Women's Movements in India. Minneapolis: University of Minnesota Press.

Ray-Bennett, N. S. (2009). Multiple disasters and policy responses in pre- and post-independence Orissa, India. Disasters, 33, 274-290.

Sahoo, S. (2013). Civil society and democratization in India: Institutions, ideologies and interest. London: Routledge.

Saz-Carranza, A., \& Ospina, S. M. (2011). The behavioral dimension of governing interorganizational goal-directed networksManaging the unity-diversity tension. Journal of Public Administration Research and Theory, 21(2), 327-365.

Schmitz, H. P., Mitchell, G. E., \& Bruno-van Vijfeijken, T. (2018). Collaboration and the future of transnational non-governmental organizations. In Paper presented at the international society of third-sector research, Amsterdam, Netherlands, 10-13 July 2018.

Shah, M. (2016). Rights-based activism, engaging the state and leveraging the markets: Possibilities of social transformation. In V. Mudgal (Ed.), Claiming India from Below: Activism and democratic Transformation. New Delhi: Routledge.

Sida. (2019). Guiding principles for Sida's engagement with and support to civil society. https://www.sida.se/English/publica tions/163770/guiding-principles-for-sidas-engagement-withand-support-to-civil-society-without-examples/. Retrieved March 6, 2020.

Sika, N. (2018). Civil society and the rise of unconventional modes of youth participation in the MENA. Middle East Law and Governance, 10, 237-263.

Sriskandarajah, D., \& Tiwana, M. (2014). Towards a multipolar civil society. SUR-International Journal on Human Rights, 20, 511-517. 
Sunata, U., \& Tosun, S. H. (2019). Assessing the civil society's role in refugee integration in Turkey: NGO-R as a New Typology. Journal of Refugee Studies, 32(4), 683-703.

Townsend, J. G., Porter, G., \& Mawdsley, E. (2004). Creating spaces of resistance: Development NGOs and their clients in Ghana, India and Mexico. Antipode, 36(5), 871-889.

UN. (2015a). Transforming our world: The 2030 agenda for sustainable development. Seventieth session, Agenda Items 15 and 116, A/Res/70/1, UN General Assembly, New York.

UN. (2015b). The Sendai framework for disaster risk reduction 2015-2030. Third UN World Conference, Sendai, Japan, March 18.

UN. (2015c). Report of the conference of the parties on its twentyfirst session. FCCC/CP/2015/10. Paris, 30 November-13 December 2015, United Nations Climate Change Secretariat, Bonn.

UN. (2016). Outcome of the world humanitarian summit. Report of the Secretary-General. 71st Session, Agenda Item 70, A/71/353, UN General Assembly, New York.

UNDP. (2004). Reducing disaster risk: A challenge for development, Bureau for Crisis Prevention and Recovery-UNDP, New York.

UNISDR. (2004). Living with risk-A global review of disaster reduction initiatives. Geneva: UN.

UNISDR. (2006). NGOs \& disaster risk reduction: A preliminary review of initiatives and progress made. Geneva: UN.

Vahanvati, M., \& Mulligan, M. (2017). A new model for effective post-disaster housing reconstruction: Lessons from Gujarat and Bihar in India. International Journal of Project Management, 35(5), 802-817.

Van Wessel, M., Katyaini, S., Mishra, Y., Naz, F., Rajeshwari, B., Manchanda, R., et al. (2019). Civil society dynamics: Shaping roles, navigating contexts, Wageningen University \& Research, Indian Institute of Technology Delhi and Lehigh University, Wageningen, the Netherlands. https://edepot.wur.nl/511476. Retrieved January 11, 2019.

Van Wessel, M., Rajeshwari, B., Naz, F., Mishra, Y., Katyaini, S., Sahoo, S., et al. (2018). Navigating possibilities of collaboration. How representative roles of diverse CSOs take shape, Wageningen University \& Research, Indian Institute of Technology Delhi and Lehigh University, Wageningen, The Netherlands.

Vaughan, A., \& Hillier, D. (2019). Ensuring impact: The role of civil society organisations in strengthening world bank disaster risk financing. https://reliefweb.int/report/world/ensuring-impactrole-civil-society-organisations-strengthening-world-bank-disas ter-risk. Retrieved October 2, 2019.

Walker, M., \& Christie, K. (2015). Where change happens: How international NGOs are shifting the focus of their advocacy \& campaigning toward the global South. London: The Eden Stanley Group Ltd.

Wetterberg, A., Brinkerhoff, D. W., \& Hertz, J. C. (2015). From compliant to capable: Balanced capacity development for local organisations. Development in Practice, 25, 966-985.

Wisner, B., Blaikie, P., Cannon, T., \& Davis, I. (2004). At risk: Natural hazards, people's vulnerability and disasters. London: Routledge.

Wong, W. H. (2012). Internal affairs: How the structure of NGOs transforms human rights. Ithaca, NY: Cornell University Press.

Publisher's Note Springer Nature remains neutral with regard to jurisdictional claims in published maps and institutional affiliations. 